\title{
CD151-a3ß1 integrin complexes suppress ovarian tumor growth by repressing slug-mediated EMT and canonical Wnt signaling
}

\author{
Lauren A. Baldwin ${ }^{1,2, *}$, John T. Hoff ${ }^{1,2, *}$, Jason Lefringhouse ${ }^{1,2, *}$, Michael Zhang ${ }^{1}$, \\ Changhe Jia ${ }^{1}$, Zeyi Liu ${ }^{1}$, Sonia Erfani ${ }^{1}$, Hongyan Jin ${ }^{1}$, Mei Xu ${ }^{1}$, Qing-Bai She ${ }^{1}$, John \\ R. van Nagell ${ }^{2}$, Chi Wang ${ }^{1}$, Li Chen ${ }^{1}$, Rina Plattner ${ }^{1}$, David M. Kaetzel ${ }^{3}$, Jia Luo ${ }^{1}$, \\ Michael Lu ${ }^{4}$, Dava West ${ }^{2}$, Chunming Liu ${ }^{1}$, Fred R. Ueland ${ }^{2}$, Ronny Drapkin ${ }^{5}$, Binhua \\ P. Zhou ${ }^{1}$ and Xiuwei H. Yang ${ }^{1}$ \\ ${ }^{1}$ Department of Pharmacology and Nutritional Science, Department of Molecular and Cellular Biochemistry, and Markey \\ Cancer Center, University of Kentucky, Lexington, KY \\ ${ }^{2}$ Division of Gynecologic Oncology, Department of Obstetrics and Gynecology, Department of Pathology \& Laboratory \\ Medicine, University of Kentucky, College of Medicine, and Markey Cancer Center, University of Kentucky, Lexington, KY \\ ${ }^{3}$ Department of Biochemistry and Molecular Biology, University of Maryland School of Medicine, Baltimore, Maryland \\ ${ }^{4}$ Department of Biomedical Science, Florida Atlantic University, Boca Raton, Florida, United States of America \\ ${ }^{5}$ Department of Cancer Biology and Pathology, Dana-Farber Cancer Institute and Harvard Medical School, Boston, MA \\ * These authors contributed equally to this work
}

Correspondence to: Xiuwei H. Yang, email: xiuwei-yang@uky.edu

Keywords: CD151 integrin EMT tumor growth ovarian cancer

Received: September 02, $2014 \quad$ Accepted: October 22, $2014 \quad$ Published: October 22, 2014

This is an open-access article distributed under the terms of the Creative Commons Attribution License, which permits unrestricted use, distribution, and reproduction in any medium, provided the original author and source are credited.

\section{ABSTRACT}

Human ovarian cancer is diagnosed in the late, metastatic stages but the underlying mechanisms remain poorly understood. We report a surprising functional link between CD151-a3 $\beta 1$ integrin complexes and the malignancy of serous-type ovarian cancer. Analyses of clinical specimens indicate that CD151 expression is significantly reduced or diminished in $\mathbf{9 0 \%}$ of metastatic lesions, while it remains detectable in $\mathbf{5 8 \%}$ of primary tumors. These observations suggest a putative tumorsuppressing role of CD151 in ovarian cancer. Indeed, our analyses show that knocking down CD151 or a 3 integrin enhances tumor cell proliferation, growth and ascites production in nude mice. These changes are accompanied by impaired cell-cell contacts and aberrant expression of E-cadherin, Mucin 5AC and fibronectin, largely reminiscent of an epithelial to mesenchymal transition (EMT)-like change. Importantly, Slug, a master regulator of EMT, is markedly elevated. Knocking down Slug partially restores CD151-a3 $\beta 1$ integrin complex-dependent suppression of cell proliferation. Moreover, disruption of these adhesion protein complexes is accompanied by a concomitant activation of canonical Wnt signaling, including elevated levels of $\beta$-catenin and Axin-2 as well as resistance to the inhibition in $\beta$-catenin-dependent transcriptional complexes. Together, our study demonstrates that CD151-a3 $\beta 1$ integrin complexes regulate ovarian tumor growth by repressing Slug-mediated EMT and Wnt signaling.

\section{INTRODUCTION}

Ovarian cancer is the leading cause of death among gynecologic cancers and the fifth most common cause of cancer related death in the United States. Nearly $70 \%$ of newly diagnosed ovarian tumors are in the late, metastatic stages of disease [1]. Clinically, treatment for serous (the most common cell type) ovarian cancer is surgical resection followed by combination platinum- and taxolbased chemotherapies. Unfortunately, $20 \%$ of patients are resistant to this regimen and most patients that are initially responsive will become resistant and ultimately 
succumb to their disease $[2,3]$. Despite the aggressive yet predictable route of tumor dissemination and high failure rate of current therapies, the molecular and cellular mechanisms underlying this cancer type remain poorly defined $[4,5]$. Hence, a better mechanistic understanding of ovarian cancer progression and metastasis is urgently needed in order to develop more effective target-based therapies.

As a family of heterodimeric adhesion receptors, integrins are widely recognized for their role in controlling tumor cell interactions with the extracellular matrix $(\mathrm{ECM})$ and neighboring cells in human epithelia-origin ovarian cancer $[1,6]$. Notably, elevated expression of RGD-based integrins, including $\alpha v \beta 3$ and $\alpha 5 \beta 1$, along with their ligands vitronectin and fibronectin, are strongly associated with accelerated ovarian tumor cell proliferation and progression [7, 8]. Such functional links appear to be related to a concomitant disruption in E-cadherin-mediated cell-cell contacts and the induction of epithelial to mesenchymal transition (EMT) $[9,10]$. For instance, in SK-OV-3ip cells, the expression of fibronectin and its receptor $\alpha 5 \beta 1$ integrin are markedly elevated upon removal of E-cadherin [7]. Thus, there is strong evidence that integrins contribute to the development and progression of human ovarian cancer by impacting cellECM and E-cadherin-dependent cell-cell interactions.

In contrast to RGD-based integrins, the role of laminin-binding (LB) integrins, including $\alpha 3 \beta 1, \alpha 6 \beta 1$ and $\alpha 6 \beta 4$, is less defined, particularly with regards to the progression of human ovarian cancer. In some studies $\alpha 6 \beta 4$ integrin is suggested to be a promoter of ovarian cancer cell invasiveness [11]. In contrast, $\alpha 3 \beta 1$ integrin appears to contribute to the maintenance of stable cellcell contact by regulating the activity of small GTPase Rho A, thereby conferring a potential tumor-suppressive function $[12,13]$. In fact, several studies have reported that expression of $\alpha 3$ integrin is inversely correlated with the metastatic potential of human ovarian cancer, particularly regarding peritoneal dissemination $[14,15]$. Thus, LB integrins are likely a central player in controlling the malignancy of ovarian cancer.

Recently, CD151, a master regulator of LB integrin function and signaling, has also been implicated in the progression of ovarian cancer. As a member of the tetraspanin family with four transmembrane domains, CD151 plays a variety of roles in multiple stages of human cancer development and progression [12, 16, 17]. For instance, CD151 has been suggested to promote tumor cell invasiveness and drug sensitivity through regulation of $\alpha 6$ integrins ( $\alpha 6 \beta 1$ and $\alpha 6 \beta 4$ ) $[18,19]$. A similar role has been recently implicated for CD151 in the progression of ovarian cancer [20]. However, there is also evidence that attenuation of CD151 expression impairs $\alpha 3 \beta 1$ integrin-dependent cell adhesion and motility over laminin substrates in a number of human carcinoma types. These effects are frequently accompanied by a concomitant disruption in E-cadherin-mediated cell-cell contacts $[12,17]$, implying a putative tumor-suppressive role for CD151- $23 \beta 1$ integrin complexes. Clinically, the direct sloughing to the peritoneal cavity is considered a primary disseminating route for ovarian cancer, as opposed to vascular or lymphatic trafficking in other carcinoma types, such as breast or prostate cancer [1]. In this regard, adhesion complexes, such as CD151- $\alpha 3 \beta 1$ integrin, may have a strong impact on ovarian cancer progression and metastasis through controlling cell-cell contact. Thus, available observations on the function of CD151 and its associated LB integrins in human ovarian cancer are conflicting and need clarification.

Here we report a functional role of CD151 and its associated $\alpha 3 \beta 1$ integrin in human serous-type ovarian cancer. Human tumor tissue arrays (TMA) were adopted for evaluation of the clinical relationship between CD151 and ovarian tumor malignancy. Xenograft and signaling analyses were then conducted to delineate the functional cascade of CD151- $\alpha 3 \beta 1$ integrin complexes during ovarian tumor growth and progression. Our results indicate that CD151- $\alpha 3 \beta 1$ integrin complexes suppress ovarian cancer malignancy largely by counteracting EMT-like processes as well as inhibiting Slug activation and canonical Wnt signaling. Hence, our study for the first time illustrates that CD151- $\alpha 3 \beta 1$ integrin complexes and associated pathways regulate ovarian tumor growth and progression and may serve as potential therapeutic targets against this lethal human cancer.

\section{RESULTS}

\section{CD151 expression is inversely associated with the malignancy of human serous-type ovarian cancer}

To evaluate the clinical significance of CD151 expression in human ovarian cancer, IHC analyses were conducted on a tumor tissue array (TMA) harboring normal ovarian tissue, as well as papillary serous adenocarcinomas varying in grade and metastatic status (Fig. 1A). By staining with a CD151-specific monoclonal antibody (Fig. 1B), we found that CD151 was only weakly expressed in the epithelium of the normal human ovary (Fig. 1C). In contrast, significant CD151 staining was detected on the plasma membrane of tumor cells, and displayed a wide range of intensities between tumor tissue samples (Fig. 1C). Notably, a moderate or strong degree of expression of CD151 was detected in 58\% of primary ovarian tumors, but in $<10 \%$ of metastatic tumors $(\mathrm{p}<0.0055)$ (Fig. 1D). A similar trend was found in another independent TMA for which matched primary and metastatic tumor samples from 7 individual patients were evaluated (Fig. 1E) $(p<0.024)$. It is also worth noting that the fallopian tube, another site for serous - 
type ovarian cancer origin [21], displayed a basal-lateral staining pattern for CD151 (Fig. 1F). Moreover, consistent with decreased CD151 protein in metastatic tumors was evidence of the heterozygous loss and a marked reduction in mRNA for this gene in the majority of TCGA ovarian tumor samples (Fig. 1G) [22]. There was, however, minimal association between CD151 expression and ovarian tumor grade or stage, which contrasts to prior reports on the expression of this protein in other cancer types $[19,23,24]$. Together, these observations indicate a significant inverse association between CD151 expression and metastatic status, suggesting a potential suppressive role of CD151 during ovarian tumor progression.

\section{CD151 suppresses ovarian cancer cell proliferation, tumor growth, and ascites production}

Next, we investigated the functional role of CD151 using cultured human serous-type ovarian tumor cell lines. Initially, our FACS analyses indicated that the degree of surface expression of CD151 and its associated LB integrins $(\alpha 3, \alpha 6$ and $\beta 4)$ were highly variable between ovarian cancer cell lines, similar to their RGD-based counterparts (e.g., $\alpha 2 \beta 1$ or $\alpha 5 \beta 1$ integrin) (Figure $2 \mathrm{~A}$ ). Interestingly, most of these lines, except OVCAR-8, displayed typical epithelia-like morphologies as reflected
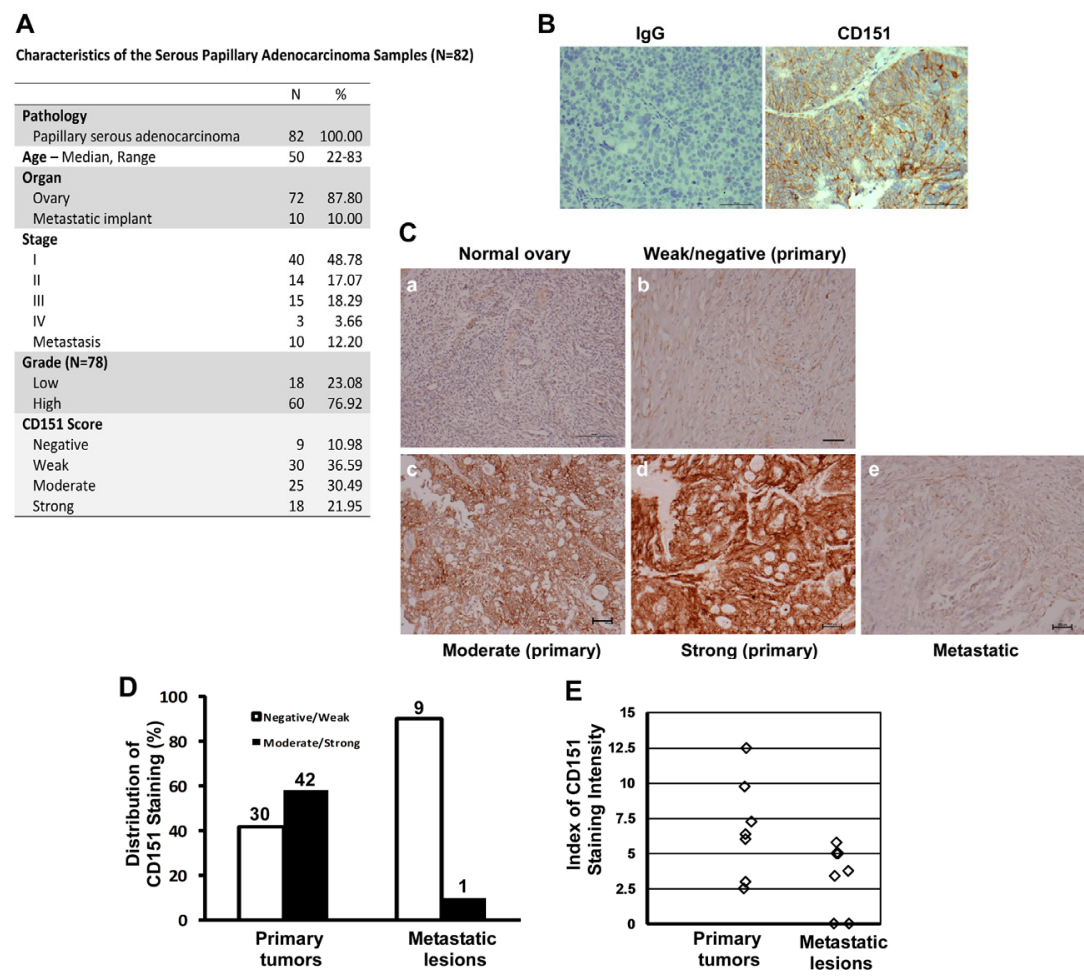

$\mathbf{E}$

Strong (primary)

Metastatic
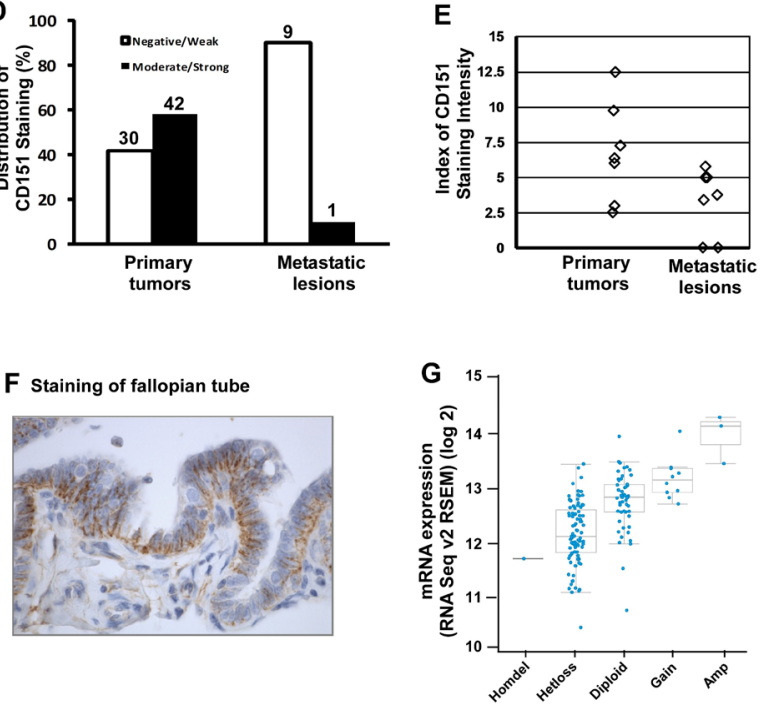

Figure 1: CD151 expression in human serous-type ovarian tumors. A Clinical parameters of TMA harboring primary tumors and metastatic lesions across age groups and grades. B Validation of IHC staining of CD151 in human ovarian tumors . Left panel: Nonimmune IgG control; Right panel: CD151antibody. C Representative images of CD151 staining of varying intensity. $a$, normal ovary. $b-d$ : ovarian tumors. $e$ : metastatic lesion. Scale bar: $100 \mu \mathrm{m}$. D Distribution of CD151 staining in primary tumors and metastatic lesions (Biomax, $\mathrm{n}=82$ ). Based on the antibody staining of tissue sections, tumor samples were divided into the negative/weak or moderate/strong group. The numbers of tumor samples per group were indicated. E Analyses of CD151 expression with in-house TMA housing 7 pairs of matched human primary and metastatic ovarian tumors. Patient characteristics described in prior studies [64]. F CD151staining in fallopian tube. G Plot of gene copy number vs mRNA expression of CD151 in the TCGA ovarian cancer samples was generated as previously described [22]. Homdel: Homozygous deletion; Hetloss: Heterozygous loss; Gain: Copy number increase; Amp: Amplification. 

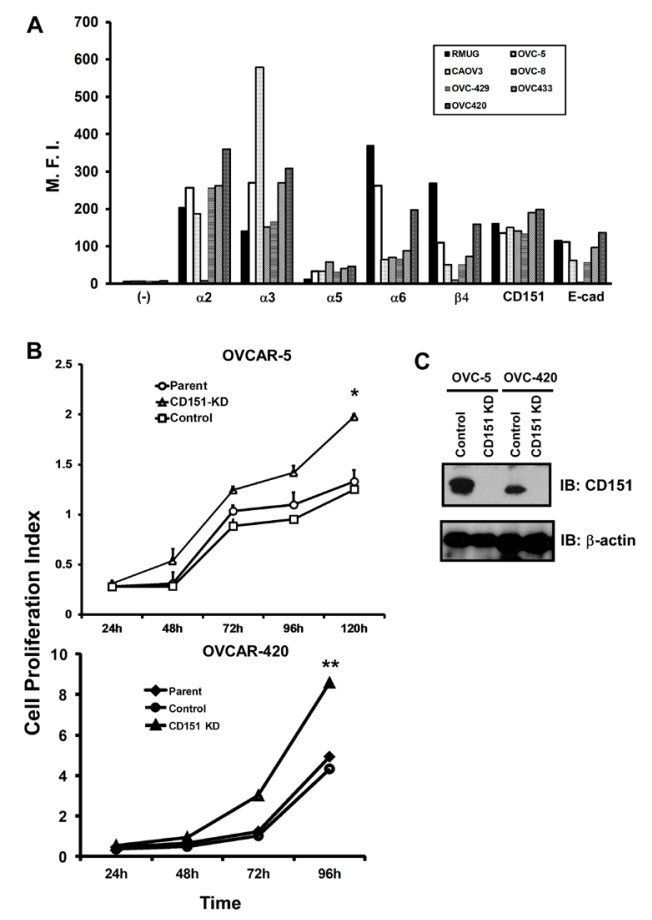

Figure 2: CD151 expression and its role in ovarian tumor cell proliferation. A The surface expression of CD151 and its molecular partners in cultured human ovarian cancer cell lines. The mean fluoresce intensity (M.F.I) represents an average of fluorescence intensity measurement from a total of 10,000 cells on flow cytometry. Semi-confluent human ovarian cancer cell lines, including OVCAR-5, OVCAR-8, OVCAR-420, OVCAR-429, OVCAR-433 and CAROV3 were detached by non-enzymatic buffer and incubated with antiCD151 (5C11), $\alpha 3$ (X8), $\alpha 6$ (GoH3), $\beta 4$ (3E1), $\alpha 2$ (IIE10) and $\alpha 5$ (BIIG2). B Changes in cell proliferation over indicated periods of time were determined using the MTT assay. Cell proliferation index was calculated on the basis of OD reading. *: p < 0.05 ; **: p <0.01. C CD151 knockdown in human ovarian cancer cell lines, OVCAR-5 and OVCAR-420. Monoclonal antibody 1A5 was used for CD151 blotting. $\beta$-actin was blotted as loading control.
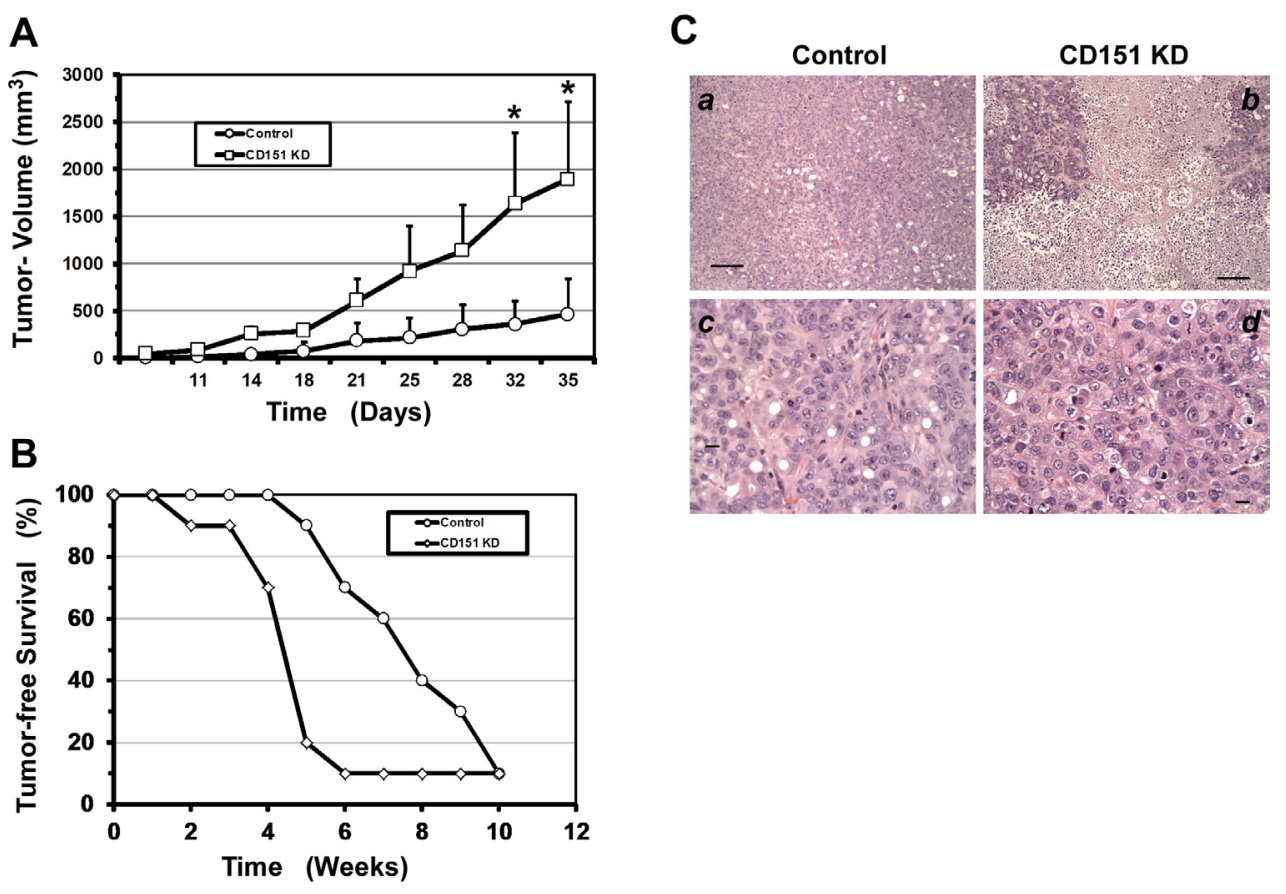

Figure 3: CD151 ablation enhances ovarian tumor growth and ascites production. A Ectopic analyses of ovarian tumor growth. The back flanks of nude mice were subcutaneously injected with control and CD151-ablated OVCAR-5 cells respectively and subsequently measured for tumor appearance and growth over the indicated periods of $(\mathrm{n}=10)$. B Kaplan-Meier survival curve. Equal numbers of immuno-deficient mice were given an intra-peritoneal injection of OVCAR-5 cells with or without CD151 ablation ( $\mathrm{n}=10)$. C H \& E stained sections of ovarian tumors derived from subcutaneously injected OVCAR-5 cells. a, c: control b, d: CD151 knockdown. Scale bar: $50 \mu \mathrm{m}$. 
by a high expression of cell surface E-cadherin.

Because OVCAR-5 and OVCAR-420 displayed significantly higher expression of CD151 and LB integrins (Figure 2A), these lines were selected as our representative models for subsequent functional analyses. As shown in Fig. 2A, upon CD151 ablation by stable expression of a well-defined shRNA from prior studies [18, 19, 25, 26], the proliferation of OVCAR-5 and OVCAR-420 cells increased by $60 \%$ and $53 \%$, respectively. However, there were minimal changes in cell motility or apoptosis of tumor cells upon CD151 removal (data not shown). Given the strong influence of CD151 ablation on cell proliferation (Fig. 2B), we next evaluated the role of CD151 in ovarian tumor growth and metastasis by applying ex vivo xenograft models in immunocompromised mice. As shown in Fig. $3 \mathrm{~A}$, tumors derived from subcutaneously injected CD151deficient OVCAR-5 cells grew significantly faster in mice, compared to the control group $(\mathrm{p}<0.05)$. Furthermore, there was enhanced ascites production and a concomitant decrease in tumor-free survival in mice injected with CD151-deficient tumor cells (4.3 vs 7.5 weeks, $p<0.005$ ) (Fig. 3B). Moreover, the tumors derived from CD151ablated OVCAR-5 cells displayed typical high-grade serous tumor histomorphologic features. Notably, these ovarian tumors had apparent nuclear pleiomorphism, prominent nucleoli, a high mitotic index, and extensive necrosis (up to $50 \%$ of tumor volume). Collectively, data from our in vitro and xenograft analyses consistently
A

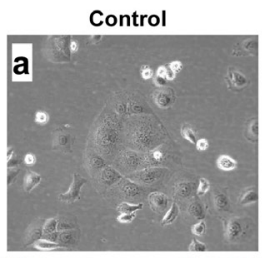

c

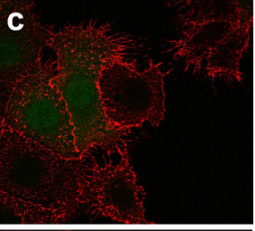

e
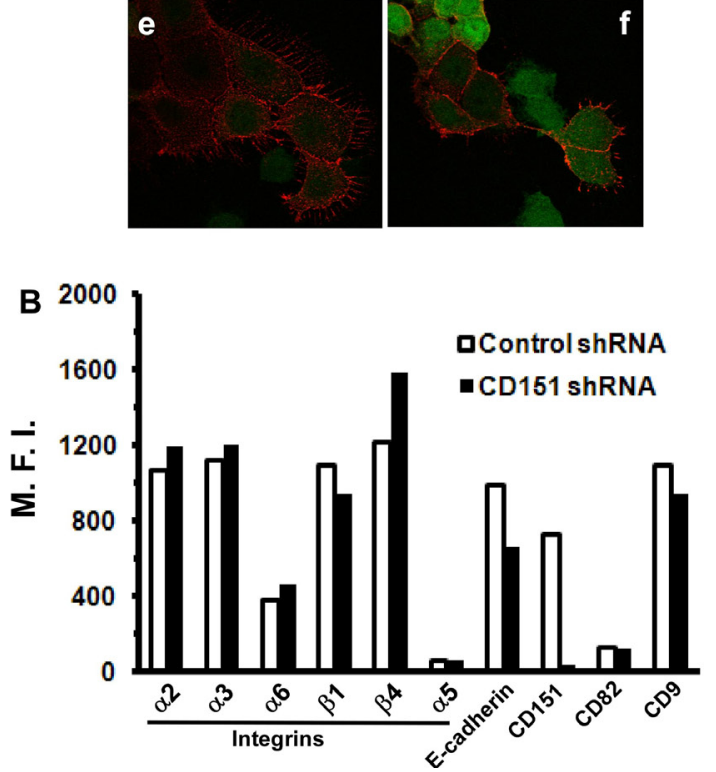

\section{Co-IP}

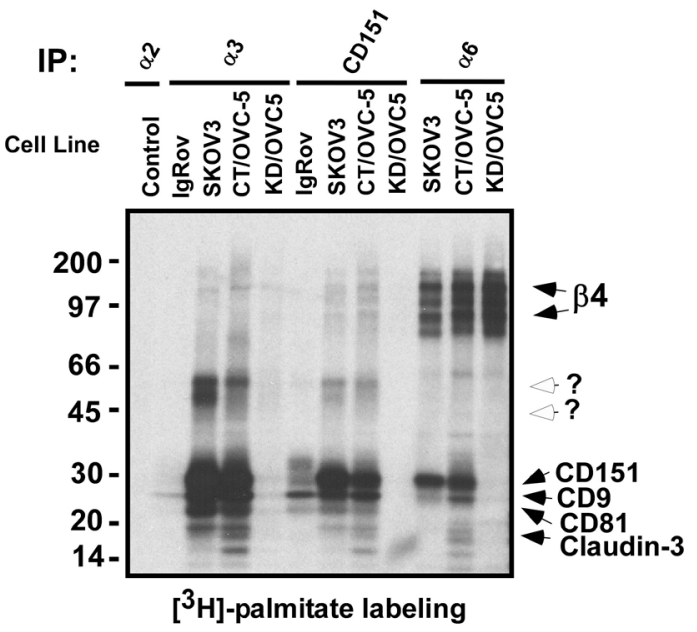

D Co-IP:

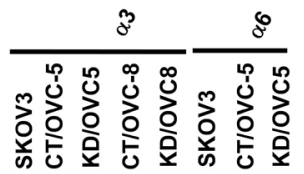

IB: Claudin-3

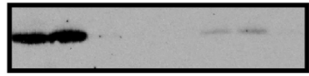

IB: Biotinlated Integrins

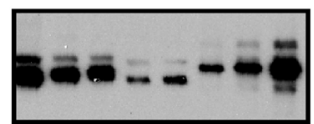

Figure 4: Impact of CD151 ablation on ovarian tumor cell-cell contact. A Typical morphologies and antibody staining of OVCAR-5 cells with or without CD151 knockdown (control or KD). a-b: Image of cells cultured for 17-24 hours; c-d staining of cell surface CD151; e-f staining of cell surface E-cadherin. c-f, cells were stained alive on ice with antibodies prior to being fixed. $a$, $c, e$ : Control; $b$, $d$, $f$ : CD151 knockdown (KD). Red-antibody staining; Green: GFP. B Change in expression of surface molecules in OVCAR-5 cells upon CD151 ablation. M.F.I ( Mean fluorescence intensity) was determined by FACS analyses. C Radiography of $\left[{ }^{3} \mathrm{H}\right]$-labeled tetraspanin- and integrin-associated protein complexes. Reciprocal co-immunoprecipitation (Co-IP) of CD151 and LB integrins was conducted for ovarian cancer cell lines IgRov, SKOV3 and OVCAR-5. Tumor cells expressing control (CT) or CD151 shRNA (KD) were included. Antibodies used for Co-IP were IIE10, X8, GÖH3 and 5C11 for integrin $\alpha 2, \alpha 3, \alpha 6$ and CD151, respectively. D Analysis of the physical interaction between LB integrins and claudin-3. Multiple ovarian tumor cell lines (SKOV3, OVC-5 and OVCAR-8) were labeled with biotin, followed by lysing in $1.0 \%$ Brij96 buffer as previously described [65]. After Co-IP with either $\alpha 3$ or $\alpha 6$ antibodies (X8 or GÖH3), the immune complexes were blotted with claudin-3-specific antibody or Avidin-conjugated HRP. 
suggest a strong suppressive role of CD151 in ovarian tumor growth and progression.

\section{Impact of CD151 removal on cell-cell contact and $\alpha 3 \beta 1$ integrin-associated protein complexes}

There is increasing evidence that the accelerated growth and progression of human ovarian carcinoma is associated with diminished or reduced cell-cell contact [1, 21]. CD151 and its associated $\alpha 3 \beta 1$ integrin are pivotal players in stabilizing cell-cell contacts in normal and malignant epithelial cells $[12,17]$. We therefore tested the notion that CD151 and $\alpha 3 \beta 1$ integrin act together to suppress ovarian tumor growth and progression by influencing tumor cell-cell contacts within the tetraspaninenriched membrane microdomain (TEMM). As shown in Fig. 4A, CD151 removal in OVCAR-5 cells led to a switch from the epithelia-like sheet to a scattered fibroblast-like appearance, accompanied by a marked reduction in surface expression of E-cadherin, compared
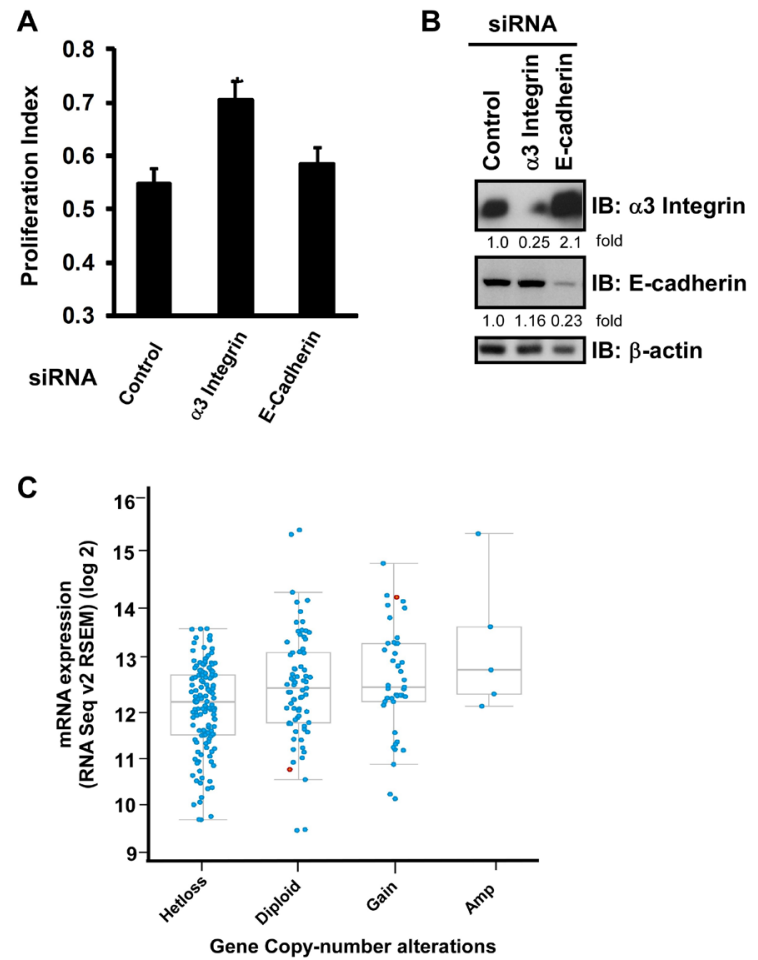

Figure 5: CD151-associated $\alpha 3$ integrin suppresses ovarian tumor cell proliferation. A Cell proliferation Index (mean $+\mathrm{SEM}, \mathrm{n}=5$ ). Cells seeded into 24 well plates were treated with indicated siRNA and $48 \mathrm{hrs}$ later analyzed by MTT assay. B Immunoblotting of $\alpha 3$ integrin and E-cadherin protein in OVCAR- 5 cells after being treated siRNA for $72 \mathrm{hrs}$. The fold change in protein level was calculated on the bases of densitometry analyses. C Plot of gene copy number vs mRNA expression of $\alpha 3$ integrin in TCGA ovarian cancer samples was generated as previously described [22]. Hetloss: Heterozygous loss; Gain: Increase in copy number; Amp: Amplification. to the control cells. Similar changes were also detected in several other ovarian tumor cell lines, including OVCAR-420 and CAROV3 (data not shown). In line with these observations is a marked decrease in the surface expression of E-cadherin when CD151 was knocked down by $90 \%$, according to our FACS analyses (Fig. 4B). On average, the surface level of E-cadherin in CD151knockdown cells decreased by $33.5 \% \pm 1.0 \%(\mathrm{n}=3$, $\mathrm{p}$ $<0.001)$. These results are consistent with prior reports on the effect of CD151 ablation in other types of human carcinoma cells $[12,17]$. Because E-cadherin-associated cell-cell contacts confer an inhibitory role in ovarian tumor cell growth and dissemination [27], our data imply that CD151 may suppress ovarian cancer malignancy by stabilizing cell-cell contacts between carcinoma cells.

Since tetraspanin molecules like CD151 are known to function within TEMM $[28,29]$, we next evaluated the impact of disrupting CD151 on the integrity of LB integrin-enriched protein complexes in ovarian cancer cells. Our co-immunoprecipitation analyses with $\left[{ }^{3} \mathrm{H}\right]$ -
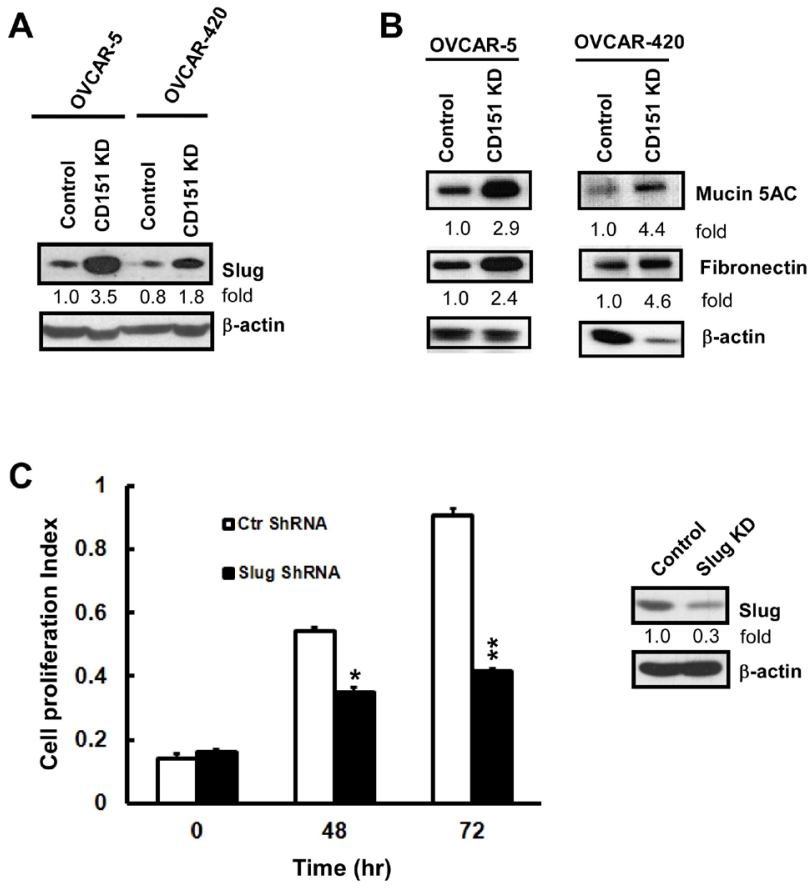

Figure 6: A functional link between CD151, EMT and Slug in ovarian cancer cells. A Effect of CD151 ablation on Slug expression in OVCAR-5 and OVCAR-420 cells. Cells were lysed in RIPA buffer and blotted with indicated antibodies. B Induction of Fibronectin and Mucin5AC in CD151-deficient tumor cells. OVCAR-5 and OVCAR-420 cells with or without CD151 knockdown (KD) were lysed in RIPA buffer and blotted with indicate antibodies. C Effect of Slug knockdown on the proliferation of CD151-deficient OVCAR-5 cells (left panel). Blotting of Slug protein in control and knockdown cells (right panel). Bottom panel, proliferation index of control and Slugknockdown cells was assessed by the MTT assay. For A-C, the fold change in protein level was estimated according to densitometry analyses. 
Table 1: List of differentially expressed genes in OVCAR-5 ovarian cancer cells upon CD151 removal. Fold changes were obtained by calculating the ratio of the mean of expression intensity for each gene. P values on the fold change were determined using paired t-test..

\begin{tabular}{|c|c|c|c|c|}
\hline Gene & Accession & Function & $\begin{array}{l}\text { Ratio of } \\
\text { Sh } \\
\text { CD151/ } \\
\text { control }\end{array}$ & P-value \\
\hline MUC5AC & AW192795 & proliferation & 34.99 & 0.002573 \\
\hline KIAA1199 & $\mathrm{AB} 033025$ & cellular proliferation & 17.57 & 0.031699 \\
\hline RNF43 & NM_017763 & promotes cell growth & 6.92 & 0.018189 \\
\hline S100A2 & NM_005978 & \begin{tabular}{|lcl} 
cell cycle progression and \\
differentiation
\end{tabular} & 5.25 & 0.028039 \\
\hline LGR4 & NM_018490 & Epithelial cell proliferation & 3.79 & 0.006977 \\
\hline ID-1 & D13889 & tumour growth and angiogenesis & 3.54 & 0.108128 \\
\hline LIF & NM_002309 & $\begin{array}{l}\text { cell growth by inhibiting } \\
\text { differentiation }\end{array}$ & 2.83 & 0.017261 \\
\hline KYNU & D55639 & catabolism of Trp metabolism & 5.4 & 0.030945 \\
\hline SLC39A4 & NM_017767 & zinc metabolism & 5.23 & 0.010953 \\
\hline CD55 & CA448665 & protein metabolism & 3.78 & 0.030651 \\
\hline AKR1B10 & NM_020299 & metabolism & 3.38 & 0.049357 \\
\hline ALDH3B1 & $\mathrm{BC} 002553$ & aldehydes metabolism & 3.34 & 0.018712 \\
\hline GCNT3 & NM_004751 & mucin-type biosynthesis & 3.34 & 0.04714 \\
\hline SLC16A3 & AL513917 & Lactic acid and pyruvate transport & 3.33 & 0.072933 \\
\hline CAMK2N1 & NM_018584 & $\mathrm{Ca}^{++}$metabolism & 2.93 & 0.022496 \\
\hline SAT1 & M55580 & Spermidine metabolism & 2.83 & 0.024851 \\
\hline Sox 4 & AL136179 & Cell fate & 4.9 & 0.024132 \\
\hline FOXP1 & AW080845 & cell fate & 4.24 & 0.01093 \\
\hline FN1 & $\mathrm{BC} 005858$ & cell motility & 4.03 & 0.039951 \\
\hline JAG1 & U73936 & cell fate & 2.69 & 0.036003 \\
\hline SLC1A1 & AW235061 & transporting glutamate & 4.13 & 0.030336 \\
\hline RGS2 & NM_002923 & Inhibits signal transduction & 3.42 & 0.017092 \\
\hline ANP32A & NM_006305 & transcriptional regulation & -2 & 0.472994 \\
\hline ANKRD12 & X80821 & transcriptional regulation & -2.19 & 0.027674 \\
\hline SNF1 & NM_014840 & Survival, invasion and metastasis & -2.34 & 0.038872 \\
\hline SGEF & AI989530 & protein binding & -2.45 & 0.013114 \\
\hline Claudin-11 & AW264204 & Tight junciton & -2.8 & 0.034391 \\
\hline BMP2K & AI735391 & differentiation. & -3.28 & 0.02009 \\
\hline COTL1 & AJ227860 & regulate the actin cytoskeleton. & -3.37 & 0.007368 \\
\hline RBMS1 & AA428240 & protein binding & -3.39 & 0.062653 \\
\hline ST6GALNAC1 & NM_030965 & glycosylaiton & -4.98 & 0.027494 \\
\hline NMRAL1 & AI080701 & Redox sensor protein. & -5.19 & 0.011539 \\
\hline CD151 & NM_004357 & cell adhesion & -7.21 & 0.179191 \\
\hline
\end{tabular}


palmitate-labeled tumor cells indicate that a number of proteins, including CD9 and CD81, were no longer associated with $\alpha 3 \beta 1$ integrin in the absence of CD151 (Fig. 4C). Interestingly, we also detected a marked decrease in the association with claudin-3 (Fig. 4D), a tight junction protein and a driver of ovarian tumor growth and metastasis [30, 31]. In line with these observations is that knockdown of $\alpha 3 \beta 1$ integrin enhanced tumor cell proliferation (Fig. 5A). However, removal of E-cadherin, had little effect on the proliferation of OVCAR-5 cells, and was accompanied by a concomitant increase in $\alpha 3$ integrin expression (Fig. 5B). In line with a suppressive role of $\alpha 3$ integrin is a trend towards reduced mRNA expression of this gene in ovarian tumors (Fig. 5C), similar to the prior analysis of CD151 (Fig. 1E). Collectively, these
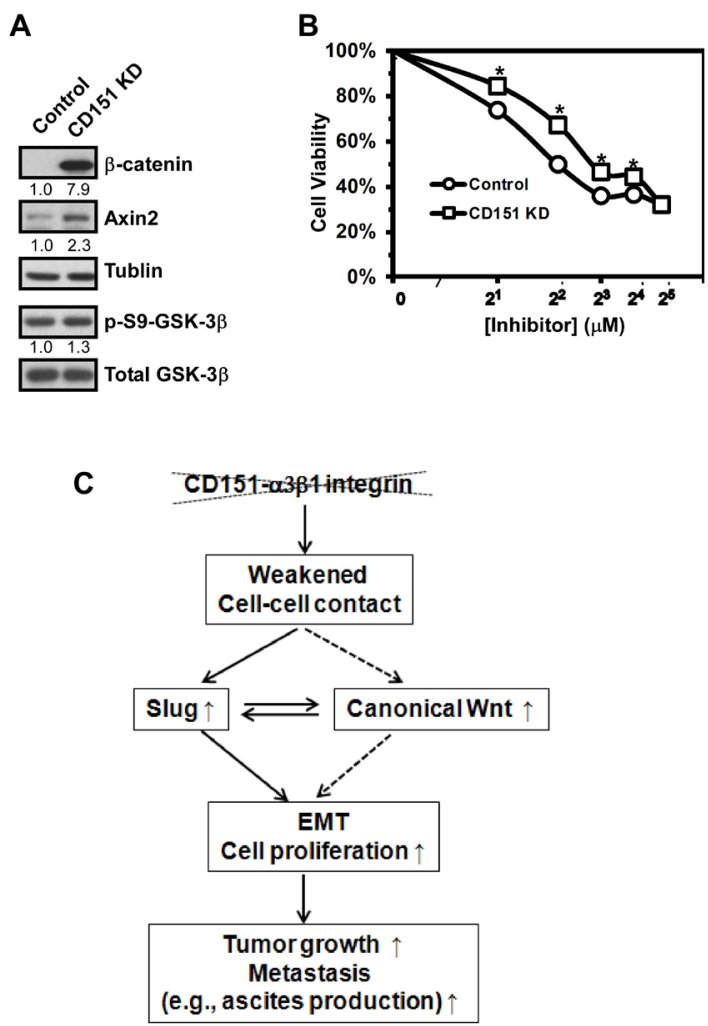

Figure 7: Induction of canonical Wnt signaling in ovarian cancer cells upon CD151 removal. A Blotting of key signaling intermediates in Wnt pathways in OVCAR-5 cells expressing control and CD151-specific shRNA. Tumor cells were lysed in RIPA buffer and blotted with antibodies against Wnt signaling molecules (i.e., $\beta$-catenin and Axin-2) as well as total and phosphorylated forms of GSK-3 $\beta$ kinase. Tublin was blotted as control. The fold change in protein level was estimated according to densitometry analyses. B Impact of CD151 knockdown on tumor cell viability in response to the treatment of ICG-001, an inhibitor disrupting the transcription within the canonical $\mathrm{Wnt} / \beta$-catenin/TCF/CBP signaling axis. OVCAR-5 cells with or without CD151 knockdown were seeded into 48 well plates and then treated with varying dosages of Wnt inhibitor for 72 hours prior to being analyzed by MTT assay. C Schematic illustration of functional roles of CD151$\alpha 3 \beta 1$ integrin complexes in ovarian cancer. results provide evidence that CD151 and $\alpha 3 \beta 1$ integrin act together to suppress human ovarian tumor growth and dissemination by regulating the integrity of cell-cell contacts among tumor cells.

\section{CD151 removal enhances the activation of EMT- inducing transcription factor Slug}

Building on our previous finding where CD151 removal gave rise to an EMT-like morphology in ovarian cancer cells (Fig. 4), we evaluated the state of EMTinducing factors. While there was minimal change in the expression of Twist, Snail or ZEB protein upon CD151 ablation (data not shown), expression of Slug proteins increased by 1.8-3.5-fold in OVCAR-5 and OVCAR-420 tumor cells (Fig. 6A). Furthermore, our genome-wide expression profiling analyses indicated that CD151 removal led to a minimal change in the mRNA of Slug (data not shown). Hence, we speculate that the increased Slug expression in CD151-deficient ovarian tumor cells may be largely attributed to post-translational regulation. In supported of elevated level of Slug protein was the change in a number of EMT-associated genes in CD151deficient OVCAR-5 cells, including fibronectin (FN1) and Mucin 5Ac (MUC5AC) [8, 32] (Table 1). Our subsequent analyses indicated that increased expression of Mucin $5 \mathrm{Ac}$ and fibronectin also occurred at the protein level (Fig. 6B). Since Slug is strongly implicated in regulating epithelial cell proliferation [33], we next tested if CD151 removal impacted ovarian tumor cell properties in a Slugdependent manner. As shown in Fig. 6C, Slug knockdown indeed led to a marked decrease in the proliferation of CD151-deficient OVCAR-5 cells. Taken together, these observations consistently suggest that CD151 plays a suppressive role in ovarian carcinoma growth largely by counteracting Slug-mediated EMT-like process. This includes alterations in cell-cell contact and a phenotypic switch to the mesenchymal phenotype as reflected by cell scattering and increased expression of fibronectin and Muc5Ac.

\section{CD151 removal in ovarian cancer cells is accompanied by an induction of Wnt signaling}

To understand how CD151 regulated Slug in ovarian cancer cells, we turned our attention to Wnt signaling, as it has been strongly connected to the activation of Slug in human carcinomas $[34,35]$. In fact, our DNA array analyses revealed marked changes in a number of Wnt pathway-related genes. Notably, upon CD151 ablation, KIAA1199 and RNF43, two newly identified regulators of Wnt signaling [36-38], increased by 18- and 7-fold at the mRNA level, respectively (Table 1). Also, similar changes in the RNF43 gene occurred at the protein level (data not shown). Moreover, CD151-deficient ovarian cancer cells 
displayed a 2-8-fold increase in $\beta$-catenin and Axin-2 proteins, two key signaling intermediates downstream of the canonical Wnt pathway (Fig. 7A). Our luciferase reporter assay with FOPFLASH reporter construct, however, revealed little change in the transcriptional activity of $\beta$-catenin/TCF complexes upon CD151 removal, regardless of Wnt3A stimulation (data not shown), implying a constitutive activation of $\beta$-cateninmediated signaling. In line with these observations is that upon treatment with ICG-001, an inhibitor specifically disrupting the transcription mediated by $\beta$-catenin/ CBP complexes [39], CD151-deficient OVCAR-5 cells displayed significantly higher viability over a range of 4 to $126 \mu \mathrm{M}$, compared to the control (Fig. 7B). It is also worth noting that there was minimal change in the activation in PI3K/AKT- or RAS/MAPPK-mediated pathways in ovarian carcinoma cells upon CD151 ablation (data not shown). Collectively, these data indicate a novel signaling cross-talk between CD151 and the canonical Wnt/ $\beta$ catenin/CBP axis-mediated pathway in ovarian cancer cells.

\section{DISCUSSION}

This study presents first clinical and experimental evidence of the suppressive role of CD151 and its associated $\alpha 3 \beta 1$ integrin in serous-type ovarian cancer. IHC and genomic analyses of human ovarian tumor tissues suggest an inverse correlation between CD151 expression and tumor metastasis. Consistent with this observation is that CD151 ablation markedly impacts ovarian tumor cell proliferation as well as tumor growth and ascites production in immuno-compromised mice. Furthermore, E-cadherin expression and cell-cell contacts in ovarian tumor cells were markedly altered upon disruption of CD151 and/or $\alpha 3 \beta 1$ integrin. In line with this EMT-like alteration is the concomitant activation of transcription factor Slug and canonical Wnt signaling. Taken together, our results demonstrate that CD151 and $\alpha 3 \beta 1$ integrin act together to suppress ovarian tumor cell growth and malignancy largely by controlling cell-cell contacts, Wnt signaling and Slug activation (Fig. 7C).

\section{CD151- $\alpha 3 \beta 1$ integrin complexes suppress tumorigenesis by counteracting the EMT-like process}

Our analyses of clinical specimens, tumor cell activities and xenograft models support a tumorsuppressive role of CD151- $\alpha 3 \beta 1$ integrin complexes in ovarian cancer. This finding is consistent with the recent studies on CD151 in human endometrial and colon cancers $[40,41]$. In addition, a similar suppressive role in tumor progression has been described for $\alpha 3 \beta 1$ integrin $[42,43]$. These observations differ from the reports on the function of these molecules in other cancer types, including breast and prostate cancer $[19,44,45]$. It has been suggested that the complex roles of LB integrins during carcinogenesis are dependent on the oncogenic contexts $[29,46]$. In this regard, the tumor-suppressive function of CD151-integrin complexes described in the current study may be partially associated with unique oncogenic activations in human serous ovarian cancer revealed by recent genome-wide analyses [4, 47].

Aside from genetic factors, the tumor-suppressive role of CD151- $\alpha 3 \beta 1$ integrin complexes in ovarian cancer may be related to their roles in maintaining stable cell-cell contact $[12,17]$. Our data show that intact CD151- $\alpha 3 \beta 1$ integrin complexes inhibit the induction of the EMT-like process (Figs. 4-6), a critical driver of ovarian cancer progression and metastasis $[1,9]$. Interestingly, in addition to decreased expression of E-cadherin, CD151 removal leads to a marked induction in fibronectin (FN) (Figs.4- 6), a strong promoter of ovarian cancer malignancy [7, 8, 48]. Such functional shift from E-cadherin- and LB integrinmediated cell-cell contact to $\alpha 5 \beta 1$ integrin-mediated cell-ECM (i.e., fibronectin) interaction may also explain why there is elevated activation of small GTPase RhoA in CD151-deficient carcinoma cells recently described by Johnson et al $[12,29]$. In support of this notion is that the engagement of fibronectin with its primary receptor, $\alpha 5 \beta 1$ integrin, is more effective in activating RhoA, compared to the interaction between laminins and their integrin receptors [49]. Consequently, our study raises the possibility that CD151- $\alpha 3 \beta 1$ integrin complexes impact ovarian cancer malignancy largely by repressing the EMTlike process and potentially the RhoA activation from fibronectin- $\alpha 5 \beta 1$ integrin-mediated signaling.

Data from the current study also suggest that the induction of the EMT-like event upon the disruption of CD151-integrin complexes may result from the activation of transcription factor Slug as well as increased cytoplasmic and nuclear expression of $\beta$-catenin. In fact, as master regulators of EMT, increased transcriptional activities of Slug and $\beta$-catenin have been associated with a broad spectrum of tumorigenic processes [50, 51]. Consistent with our observations (Figs. 3-5) is the promoting role of these two transcription factors in ovarian cancer development and malignancy described by multiple studies [9, 52-54]. At the present time, however, how CD151 removal leads to the increased expression or activation of Slug and $\beta$-catenin in ovarian cancer remains unclear.

\section{Functional links between CD151- $\alpha 3 \beta 1$ integrin complexes and oncogenic pathways}

One of the surprising observations from the current study is the inverse functional link between CD151- $\alpha 3 \beta 1$ integrin complexes and the signaling of canonical Wnt 
pathways in ovarian cancer. This finding is consistent with recent studies on tetraspanin molecules, such as tetraspanin CD9, which suppresses Wnt signalingdependent tumor cell proliferation and growth $[55,56]$. In addition, these studies all point to the repression of $\beta$-catenin-dependent canonical Wnt signaling by tetraspanin molecules. Mechanistically, since minimal change was detected in the mRNA levels of Frizzed or LRP5/LRP6 in our study, the regulation of canonical Wnt signaling by CD151-integrin complexes may not occur at the receptor level. This observation is also in contrast to a recent report on the increase in LRP5 mRNA in CD151null mouse tissues [57], raising the possibility of a tissuespecific effect of CD151 on Wnt signaling. Intriguingly, we also detected a marked elevation in the expression of KIAA1199 and RNF43 in CD151-deficient ovarian tumor cells (Table 1), two newly identified negative regulators of Wnt signaling [38, 58], implying a potential feedback mechanism related to CD151 function. Collectively, the marked changes in these important effectors and regulators of Wnt signaling underscore the complex signaling roles of CD151- $\alpha 3 \beta 1$ integrin complexes in ovarian tumor growth and progression.

\section{Sequestering of pro-tumorigenic regulators within TEMM by CD151-integrin complexes}

Additional evidence supporting the suppressive role of CD151- $\alpha 3 \beta 1$ integrin complexes in ovarian cancer comes from the loss of tumor-promoting molecules within CD151-deficient TEMM, such as CD9 and claudin-3 (Fig. 4). In fact, both CD9 and claudin-3 proteins are present in TEMM on tumor cells $[28,29,59]$ and have been strongly linked to cancer malignancy $[30,31,60]$. In particular, CD9 has been shown to promote ovarian cancer cell dissemination by influencing integrin activation [31]. It has also been suggested that claudin-3 drives ovarian tumor progression and metastasis by controlling cell-cell contacts and Wnt signaling [61]. Conceivably, CD151 may regulate ovarian tumor growth and dissemination, at least in part, by sequestering the function of tumor-promoting molecules such as CD9 and claudin-3 within the TEMM in ovarian tumor cells.

\section{Clinical significance of CD151-integrin complexes as ovarian tumor suppressors}

Results from the current study have important implications for the diagnosis and treatment of human ovarian cancer. In particular, we found that two secreted proteins, Mucin $5 \mathrm{Ac}$ and fibronectin, exhibit elevated expression upon the disruption of CD151- $\alpha 3 \beta 1$ integrin complexes (Table $1 \&$ Fig. 6). In addition, like CA125, a common biomarker for ovarian cancer [62, 63], Mucin 5Ac belongs to the Mucin family, and has been implicated in promoting ovarian cancer progression [32]. Hence, evaluating these CD151- $\alpha 3 \beta 1$ integrin complexassociated effectors as new biomarkers may aid in the future detection or diagnosis of human ovarian cancer malignancy. Moreover, the pro-malignancy factors or pathways counteracted by $\mathrm{CD} 151$ and $\alpha 3 \beta 1$ integrin may serve as therapeutic targets against ovarian cancer. Based on our observations (Figs. 6-7), the inhibitors of the transcriptional factor Slug or $\beta$-catenin-dependent canonical Wnt signaling pathway (Figs. 6-7) are potentially effective in disrupting the malignancy of ovarian cancer.

In summary, our study demonstrates a suppressive role of CD151 and associated $\alpha 3 \beta 1$ integrin in ovarian tumor cell proliferation, growth and ascites production. Mechanistically, CD151 conveys its tumor-suppressing function largely by stabilizing $\alpha 3 \beta 1$ integrin- and E-cadherin-mediated cell-cell contact, while counteracting the EMT-like process through repressing the activation of Slug and canonical Wnt signaling. As such, our study has identified a new set of molecular pathways and regulators as candidate biomarkers and therapeutic targets for the treatment of aggressive serous-type ovarian cancer.

\section{METHODS}

\section{Human ovarian TMA, cell lines and culture}

TMA harboring paraffin-embedded human ovarian tumors prepared from a broad spectrum of ovarian cancer patients (Supplementary Table S1) were obtained from Biomax (NY). The in-house TMA containing matched primary tumors and metastatic lesions from individual patients were described in a prior study [64]. Human ovarian cancer cell lines, including CAOV3, OVCAR-5, OVCAR-8, OVCAR-420, OVCAR-429, OVCAR-433, IgRov and SK-OV-3, were purchased from ATCC (Manassas, VA). All cell lines were cultured in RPMI 1640 supplemented in $10 \% \mathrm{FBS}$ under $5 \% \mathrm{CO}_{2}$.

\section{Antibodies and reagents}

Anti-integrin $\alpha 2$ (IIE10), $\alpha 3$ (X8), $\alpha 6$ (ELE) and $\beta 1$ (P5D2), along with anti-tetraspanin CD151 (5C11), CD9 (C9BB) and CD82 (M104), were raised in-house as described in prior studies [19]. The CD151specific monoclonal antibody used for IHC analyses was obtained from Leica Microsystems, Inc. (Buffalo Grove, IL). Antibodies against fibronectin and Mucin $5 \mathrm{Ac}$ were purchased from Sigma-Aldrich (St. Louis, $\mathrm{MO}$ ). Antibodies recognizing total and phospho-Akt or MAPK or GSK3- $\beta$, along with those against Snail, Slug, LRP5, LPR6 and Axin-2, were obtained from Cell Signaling Technology (Danvers, MA). Antibodies against 
E-cadherin, Twist, Zeb1 and Zeb2 were purchased from Santa Cruz Biotechnology (Santa Cruz, CA). Matrigel invasion chambers and anti- $\beta 4$ integrin antibody were purchased from BD Biosciences (Franklin Lake, NJ). ICG-001, an inhibitor of canonical Wnt signaling, was obtained from Selleckchem (Houston, TX).

\section{Assays for cell proliferation, apoptosis, adhesion, motility and invasion}

Changes in ovarian tumor cell proliferation or viability when subjected to Wnt inhibitor treatment were determined by MTT assay. Change in cell cycle and apoptosis was measured by staining fixed cells with propidium iodide, followed by analyses on flow cytometry. The assays for cell adhesion and invasion were carried out as previously described [19]. For measurement of random cell motility, cells were seeded into 24 well plates at 1.5 $\mathrm{x} 10^{4}$ per well and placed inside OKALAB incubator with a heater and gas mixer constant at $37{ }^{\circ} \mathrm{C}$ and $5 \%$ $\mathrm{CO}_{2}$. The cells were imaged at $20 \mathrm{~min}$ intervals for the indicated length of time with a Nikon Automated Eclipse Ti-E inverted microscope. Quantitation of individual cell movement indicated by distance, was measured by using Nikon NIS-Elements Advanced Analysis Software as previously described [18] .

\section{RNAi, transfection, FACS , immunofluorescence analysis (IF) and IHC analyses}

Stable knockdown of CD151 and Slug was carried out as previously described. The siRNA for $\alpha 3$ integrin was obtained from Thermo Scientific (Pittsburgh, PA) as described in our prior study and siRNA for E-Cadherin was purchased from Santa Cruz Biotechnology (Santa Cruz, CA). The shRNA for Slug was purchased from Addgene (Cambridge, MA). The surface expression of integrins and tetraspanins was determined by FACS analyses of 10,000 cells on flow cytometry at UK core facility. For indirect immunofluorescence analyses of cell surface proteins, cells were incubated with primary and fluorescence-conjugated antibodies on ice before being fixed in $2 \%$ paraformaldehyde, and visualized under a confocal microscope.

IHC analyses of TMAs and human fallopian tube tissues were conducted essentially as described in our prior study $[18,19]$. In brief, the antigen was retrieved by use of the decloaking chamber in the presence of $0.01 \mathrm{~mol} / \mathrm{L}$ EDTA buffer ( $\mathrm{pH}$ 9.0). After blocking in goat serum, TMA slides were incubated with CD151specific monoclonal antibody, followed by incubation with biotinylated secondary antibody, and finally developed using DAB Kit (BD Bioscience, San Jose, $\mathrm{CA}$ ) and counterstained with hematoxylin. The scoring of immunostaining was evaluated on the bases of staining intensity and percentages of positively stained areas by three independent staff members as previously described [19].

\section{Signaling, $\quad\left[{ }^{3} \mathbf{H}\right]-$ palmitate labeling, co- immunoprecipitation and western blot analyses}

For evaluation of the effect of CD151 on cell signaling, semi-confluent ovarian cancer cells grown under various conditions were lysed in RIPA buffer supplemented with protease and phosphatase inhibitors, and subsequently blotted with indicated antibodies. The compositions of RIPA buffer were described elsewhere [26]. For co-immunoprecipitation of tetraspanin-integrin complexes, cultured human ovarian cancer cells were radio-labeled with $0.2 \mu \mathrm{Ci}\left[{ }^{3} \mathrm{H}\right]$-palmitate for 3 hours prior to being lysed in $1 \%$ Brij-96 buffer as previously described [65]. The biotin-labeling of cell surface molecules were carried out as previously described [65]. The cell lysates were then immunoprecipitated with indicated tetraspanin or integrin-specific antibodies. The immune complexes or cell lysates were separated on SDS-PAGE, transferred onto a nitrocellulose membrane and exposed to radiography or blotted with indicated antibodies.

\section{Xenograft analyses}

Analyses of ovarian tumor growth were conducted by subcutaneously injecting control and CD151-ablated OVCAR-5 cells into the flanks of immune-compromised nude mice (Charles River, MA) at $1 \times 10^{6}$ cells per site. For analyses of ascites production, $1 \times 10^{6}$ (in $200 \mu \mathrm{l}$ ) OVCAR-5 cells were injected into the peritoneal body cavity of nude mice at 5 animals per group. During the animal studies, mice were monitored daily for the initial appearance of palpable tumors or an enlarged abdomen due to ascites production. The tumor sizes were measured twice a week with calipers and volumes were calculated using the formula of length $\mathrm{x}$ width $\mathrm{x}$ height $\mathrm{x}$ 0.52. All animals were terminated with the apparent appearance of disease. At the end of the experiments, tumors derived from subcutaneously injected mice were collected and fixed in 10\% neutral formalin (Sigma-Aldrich, St. Louis, $\mathrm{MO}$ ) and stored in $70 \%$ ethanol prior to being embedded into paraffin blocs for $\mathrm{H} \& \mathrm{E}$ staining.

\section{Gene expression profiling analyses}

To conduct DNA array analyses, total RNA was extracted from semi-confluent human OVCAR-5 cells expressing control and CD151-specific shRNA by use of the Trizol method (Life Technologies, Grand Island, NY) and subsequently analyzed with Affiymatrix U133 PLUS 2 arrays. 


\section{Statistical analyses}

All experiments described in the study were independently repeated. The Fisher exact test was performed on the association of CD151 expression in metastatic lesions of human ovarian tumors in TMA. The paired student t-test was conducted to assess the difference in CD151 staining between 7 paired human primary ovarian tumors and metastatic lesions or the impact of CD151 knockdown on ovarian tumor growth. Difference in tumor-free survival was assessed by the log-rank test.

\section{ACKNOWLEDGMENTS}

This study was supported in part through DOD Ovarian Cancer Research Program W81XWH-08-1-0120, Franchi Investigator Award/Dana-Farber Cancer Institute, S. G. Komen for the Cure career catalyst award, NIH COBRE/pilot project fund and A pilot project grant from American Cancer Society \#IRG 85-001-25 to X.H. Yang.

\section{REFERENCES}

1. Lengyel E. Ovarian cancer development and metastasis. The American journal of pathology. 2010; 177(3):10531064.

2. Vaughan S, Coward JI, Bast RC, Jr., Berchuck A, Berek JS, Brenton JD, Coukos G, Crum CC, Drapkin R, Etemadmoghadam D, Friedlander M, Gabra H, Kaye SB, Lord CJ, Lengyel E, Levine DA, et al. Rethinking ovarian cancer: recommendations for improving outcomes. Nature reviews Cancer. 2011; 11(10):719-725.

3. Landen CN, Jr., Birrer MJ and Sood AK. Early events in the pathogenesis of epithelial ovarian cancer. Journal of clinical oncology : official journal of the American Society of Clinical Oncology. 2008; 26(6):995-1005.

4. Integrated genomic analyses of ovarian carcinoma. Nature. 2011; 474(7353):609-615.

5. Hiss D. Optimizing molecular-targeted therapies in ovarian cancer: the renewed surge of interest in ovarian cancer biomarkers and cell signaling pathways. Journal of oncology. 2012; 2012:737981.

6. Saad AF, Hu W and Sood AK. Microenvironment and pathogenesis of epithelial ovarian cancer. Hormones \& cancer. 2010; 1(6):277-290.

7. Sawada K, Mitra AK, Radjabi AR, Bhaskar V, Kistner EO, Tretiakova M, Jagadeeswaran S, Montag A, Becker A, Kenny HA, Peter ME, Ramakrishnan V, Yamada SD and Lengyel E. Loss of E-cadherin promotes ovarian cancer metastasis via alpha 5-integrin, which is a therapeutic target. Cancer Res. 2008; 68(7):2329-2339.

8. Mitra AK, Sawada K, Tiwari P, Mui K, Gwin K and Lengyel E. Ligand-independent activation of c-Met by fibronectin and alpha(5)beta(1)-integrin regulates ovarian cancer invasion and metastasis. Oncogene. 2011; 30(13):1566-1576.

9. Kurrey NK, K A and Bapat SA. Snail and Slug are major determinants of ovarian cancer invasiveness at the transcription level. Gynecologic oncology. 2005; 97(1):155165.

10. Davidson B, Trope CG and Reich R. Epithelialmesenchymal transition in ovarian carcinoma. Frontiers in oncology. 2012; 2:33.

11. Choi YP, Kim BG, Gao MQ, Kang S and Cho NH. Targeting ILK and beta4 integrin abrogates the invasive potential of ovarian cancer. Biochemical and biophysical research communications. 2012; 427(3):642-648.

12. Johnson JL, Winterwood N, DeMali KA and Stipp CS. Tetraspanin CD151 regulates RhoA activation and the dynamic stability of carcinoma cell-cell contacts. J Cell Sci. 2009; 122(Pt 13):2263-2273.

13. Zhang F, Michaelson JE, Moshiach S, Sachs N, Zhao W, Sun Y, Sonnenberg A, Lahti JM, Huang H and Zhang XA. Tetraspanin CD151 maintains vascular stability by balancing the forces of cell adhesion and cytoskeletal tension. Blood. 2011; 118(15):4274-4284.

14. Gourley C, Paige AJ, Taylor KJ, Ward C, Kuske B, Zhang J, Sun M, Janczar S, Harrison DJ, Muir M, Smyth JF and Gabra H. WWOX gene expression abolishes ovarian cancer tumorigenicity in vivo and decreases attachment to fibronectin via integrin alpha3. Cancer Res. 2009; 69(11):4835-4842.

15. Suzuki N, Higashiguchi A, Hasegawa Y, Matsumoto H, Oie S, Orikawa K, Ezawa S, Susumu N, Miyashita K and Aoki D. Loss of integrin alpha3 expression associated with acquisition of invasive potential by ovarian clear cell adenocarcinoma cells. Human cell. 2005; 18(3):147-155.

16. Kazarov AR, Yang X, Stipp CS, Sehgal B and Hemler ME. An extracellular site on tetraspanin CD151 determines alpha 3 and alpha 6 integrin-dependent cellular morphology. Journal of Cell Biology. 2002; 158(7):1299-1309.

17. Chattopadhyay N, Wang Z, Ashman LK, Brady-Kalnay SM and Kreidberg JA. alpha3beta1 integrin-CD151, a component of the cadherin-catenin complex, regulates PTPmu expression and cell-cell adhesion. Journal of Cell Biology. 2003; 163(6):1351-1362.

18. Deng X, Li Q, Hoff J, Novak M, Yang H, Jin H, Erfani SF, Sharma C, Zhou P, Rabinovitz I, Sonnenberg A, Yi Y, Stipp CS, Kaetzel DM, Hemler ME and Yang XH. IntegrinAssociated CD151 Drives ErbB2-Evoked Mammary Tumor Onset and Metastasis. Neoplasia. 2012; 14(8):678-689.

19. Yang XWH, Richardson AL, Torres-Arzayus MI, Zhou PC, Sharma C, Kazarov AR, Andzelm MM, Strominger JL, Brown M and Hemler ME. CD151 accelerates breast cancer by regulating alpha(6) integrin function, signaling, and molecular organization. Cancer Res. 2008; 68(9):32043213.

20. Mosig RA, Lin L, Senturk E, Shah H, Huang F, 
Schlosshauer P, Cohen S, Fruscio R, Marchini S, D’Incalci M, Sachidanandam R, Dottino $\mathrm{P}$ and Martignetti JA. Application of RNA-Seq transcriptome analysis: CD151 is an Invasion/Migration target in all stages of epithelial ovarian cancer. Journal of ovarian research. 2012; 5:4.

21. Vang R, Shih Ie M and Kurman RJ. Ovarian lowgrade and high-grade serous carcinoma: pathogenesis, clinicopathologic and molecular biologic features, and diagnostic problems. Advances in anatomic pathology. 2009; 16(5):267-282.

22. Cerami E, Gao J, Dogrusoz U, Gross BE, Sumer SO, Aksoy BA, Jacobsen A, Byrne CJ, Heuer ML, Larsson E, Antipin Y, Reva B, Goldberg AP, Sander C and Schultz $\mathrm{N}$. The cBio cancer genomics portal: an open platform for exploring multidimensional cancer genomics data. Cancer discovery. 2012; 2(5):401-404.

23. Hashida H, Takabayashi A, Tokuhara T, Hattori N, Taki T, Hasegawa H, Satoh S, Kobayashi N, Yamaoka Y and Miyake M. Clinical significance of transmembrane 4 superfamily in colon cancer. British journal of cancer. 2003; 89(1):158-167.

24. Gesierich S, Paret C, Hildebrand D, Weitz J, Zgraggen K, Schmitz-Winnenthal FH, Horejsi V, Yoshie O, Herlyn $\mathrm{D}$, Ashman LK and Zoller M. Colocalization of the tetraspanins, CO-029 and CD151, with integrins in human pancreatic adenocarcinoma: impact on cell motility. Clinical Cancer Research. 2005; 11(8):2840-2852.

25. Winterwood NE, Varzavand A, Meland MN, Ashman LK and Stipp CS. A critical role for tetraspanin CD151 in alpha3beta 1 and alpha6beta4 integrin-dependent tumor cell functions on laminin-5. Molecular biology of the cell. 2006; 17(6):2707-2721.

26. Yang XH, Flores LM, Li Q, Zhou P, Xu F, Krop IE and Hemler ME. Disruption of laminin-integrin-CD151-focal adhesion kinase axis sensitizes breast cancer cells to ErbB2 antagonists. Cancer Res. 2010; 70(6):2256-2263.

27. Vergara D, Merlot B, Lucot JP, Collinet P, Vinatier D, Fournier I and Salzet M. Epithelial-mesenchymal transition in ovarian cancer. Cancer letters. 2010; 291(1):59-66.

28. Hemler ME. Tetraspanin functions and associated microdomains. Nature Reviews Molecular Cell Biology. 2005; 6(10):801-811.

29. Hemler ME. Tetraspanin proteins promote multiple cancer stages. Nature reviews Cancer. 2014; 14(1):49-60.

30. Huang YH, Bao Y, Peng W, Goldberg M, Love K, Bumcrot DA, Cole G, Langer R, Anderson DG and Sawicki JA. Claudin-3 gene silencing with siRNA suppresses ovarian tumor growth and metastasis. Proceedings of the National Academy of Sciences of the United States of America. 2009; 106(9):3426-3430.

31. Furuya M, Kato H, Nishimura N, Ishiwata I, Ikeda H, Ito $\mathrm{R}$, Yoshiki $\mathrm{T}$ and Ishikura $\mathrm{H}$. Down-regulation of CD9 in human ovarian carcinoma cell might contribute to peritoneal dissemination: morphologic alteration and reduced expression of beta1 integrin subsets. Cancer Res. 2005; 65(7):2617-2625.

32. Han L, Pansare V, Al-Abbadi M, Husain M and Feng J. Combination of MUC5ac and WT-1 immunohistochemistry is useful in distinguishing pancreatic ductal carcinoma from ovarian serous carcinoma in effusion cytology. Diagnostic cytopathology. 2010; 38(5):333-336.

33. Nassour M, Idoux-Gillet Y, Selmi A, Come C, Faraldo ML, Deugnier MA and Savagner P. Slug controls stem/ progenitor cell growth dynamics during mammary gland morphogenesis. PloS one. 2012; 7(12):e53498.

34. Wu ZQ, Li XY, Hu CY, Ford M, Kleer CG and Weiss SJ. Canonical Wnt signaling regulates Slug activity and links epithelial-mesenchymal transition with epigenetic Breast Cancer 1, Early Onset (BRCA1) repression. Proceedings of the National Academy of Sciences of the United States of America. 2012; 109(41):16654-16659.

35. Liu YN, Abou-Kheir W, Yin JJ, Fang L, Hynes P, Casey O, Hu D, Wan Y, Seng V, Sheppard-Tillman H, Martin P and Kelly K. Critical and reciprocal regulation of KLF4 and SLUG in transforming growth factor beta-initiated prostate cancer epithelial-mesenchymal transition. Molecular and cellular biology. 2012; 32(5):941-953.

36. Hao HX, Xie Y, Zhang Y, Charlat O, Oster E, Avello M, Lei H, Mickanin C, Liu D, Ruffner H, Mao X, Ma Q, Zamponi R, Bouwmeester T, Finan PM, Kirschner MW, et al. ZNRF3 promotes Wnt receptor turnover in an R-spondin-sensitive manner. Nature. 2012; 485(7397):195200.

37. Jiang X, Hao HX, Growney JD, Woolfenden S, Bottiglio C, Ng N, Lu B, Hsieh MH, Bagdasarian L, Meyer R, Smith TR, Avello M, Charlat O, Xie Y, Porter JA, Pan S, et al. Inactivating mutations of RNF43 confer Wnt dependency in pancreatic ductal adenocarcinoma. Proceedings of the National Academy of Sciences of the United States of America. 2013; 110(31):12649-12654.

38. Birkenkamp-Demtroder K, Maghnouj A, Mansilla F, Thorsen K, Andersen CL, Oster B, Hahn S and Orntoft TF. Repression of KIAA1199 attenuates Wnt-signalling and decreases the proliferation of colon cancer cells. British journal of cancer. 2011; 105(4):552-561.

39. Takahashi-Yanaga F and Kahn M. Targeting Wnt signaling: can we safely eradicate cancer stem cells? Clinical cancer research : an official journal of the American Association for Cancer Research. 2010; 16(12):3153-3162.

40. Voss MA, Gordon N, Maloney S, Ganesan R, Ludeman L, McCarthy K, Gornall R, Schaller G, Wei W, Berditchevski $\mathrm{F}$ and Sundar S. Tetraspanin CD151 is a novel prognostic marker in poor outcome endometrial cancer. British journal of cancer. 2011; 104(10):1611-1618.

41. Chien CW, Lin SC, Lai YY, Lin BW, Lee JC and Tsai SJ. Regulation of CD151 by hypoxia controls cell adhesion and metastasis in colorectal cancer. Clinical Cancer Research. 2008; 14(24):8043-8051. 
42. Owens DM and Watt FM. Influence of beta1 integrins on epidermal squamous cell carcinoma formation in a transgenic mouse model: alpha3beta1, but not alpha2beta1, suppresses malignant conversion. Cancer Res. 2001; 61(13):5248-5254.

43. Sachs N, Secades P, van Hulst L, Kreft M, Song JY and Sonnenberg A. Loss of integrin alpha3 prevents skin tumor formation by promoting epidermal turnover and depletion of slow-cycling cells. Proceedings of the National Academy of Sciences of the United States of America. 2012.

44. Mitchell K, Svenson KB, Longmate WM, Gkirtzimanaki K, Sadej R, Wang X, Zhao J, Eliopoulos AG, Berditchevski $\mathrm{F}$ and Dipersio CM. Suppression of integrin alpha3beta 1 in breast cancer cells reduces cyclooxygenase- 2 gene expression and inhibits tumorigenesis, invasion, and crosstalk to endothelial cells. Cancer Res. 2010; 70(15):63596367.

45. Ang J, Lijovic M, Ashman LK, Kan K and Frauman AG. CD151 protein expression predicts the clinical outcome of low-grade primary prostate cancer better than histologic grading: a new prognostic indicator? Cancer epidemiology, biomarkers \& prevention : a publication of the American Association for Cancer Research, cosponsored by the American Society of Preventive Oncology. 2004; 13(11 Pt 1):1717-1721.

46. Raymond K, Kreft M, Song JY, Janssen H and Sonnenberg A. Dual Role of alpha6beta4 integrin in epidermal tumor growth: tumor-suppressive versus tumor-promoting function. Molecular biology of the cell. 2007; 18(11):42104221.

47. Kan Z, Jaiswal BS, Stinson J, Janakiraman V, Bhatt D, Stern HM, Yue P, Haverty PM, Bourgon R, Zheng J, Moorhead M, Chaudhuri S, Tomsho LP, Peters BA, Pujara $\mathrm{K}$, Cordes S, et al. Diverse somatic mutation patterns and pathway alterations in human cancers. Nature. 2010; 466(7308):869-873.

48. Kenny HA, Kaur S, Coussens LM and Lengyel E. The initial steps of ovarian cancer cell metastasis are mediated by MMP-2 cleavage of vitronectin and fibronectin. The Journal of clinical investigation. 2008; 118(4):1367-1379.

49. Gu JG, Sumida Y, Sanzen N and Sekiguchi K. Laminin-10/11 and fibronectin differentially regulate integrin-dependent rho and rac activation via p130(Cas)CrkII-DOCK180 pathway. Journal of Biological Chemistry. 2001; 276(29):27090-27097.

50. Guo W, Keckesova Z, Donaher JL, Shibue T, Tischler V, Reinhardt F, Itzkovitz S, Noske A, Zurrer-Hardi U, Bell G, Tam WL, Mani SA, van Oudenaarden A and Weinberg RA. Slug and Sox 9 cooperatively determine the mammary stem cell state. Cell. 2012; 148(5):1015-1028.

51. Dhasarathy A, Phadke D, Mav D, Shah RR and Wade PA. The transcription factors Snail and Slug activate the transforming growth factor-beta signaling pathway in breast cancer. PloS one. 2011; 6(10):e26514.

52. Yang D, Sun Y, Hu L, Zheng H, Ji P, Pecot CV, Zhao Y,
Reynolds S, Cheng H, Rupaimoole R, Cogdell D, Nykter M, Broaddus R, Rodriguez-Aguayo C, Lopez-Berestein G, Liu J, et al. Integrated analyses identify a master microRNA regulatory network for the mesenchymal subtype in serous ovarian cancer. Cancer cell. 2013; 23(2):186-199.

53. Elloul S, Elstrand MB, Nesland JM, Trope CG, Kvalheim G, Goldberg I, Reich R and Davidson B. Snail, Slug, and Smad-interacting protein 1 as novel parameters of disease aggressiveness in metastatic ovarian and breast carcinoma. Cancer. 2005; 103(8):1631-1643.

54. Haslehurst AM, Koti M, Dharsee M, Nuin P, Evans K, Geraci J, Childs T, Chen J, Li J, Weberpals J, Davey S, Squire J, Park PC and Feilotter H. EMT transcription factors snail and slug directly contribute to cisplatin resistance in ovarian cancer. BMC cancer. 2012; 12:91.

55. Huang CL, Liu D, Masuya D, Kameyama K, Nakashima T, Yokomise H, Ueno M and Miyake M. MRP-1/CD9 gene transduction downregulates Wnt signal pathways. Oncogene. 2004; 23(45):7475-7483.

56. Chairoungdua A, Smith DL, Pochard P, Hull M and Caplan MJ. Exosome release of beta-catenin: a novel mechanism that antagonizes Wnt signaling. J Cell Biol. 2010; 190(6):1079-1091.

57. Tsujino K, Takeda Y, Arai T, Shintani Y, Inagaki R, Saiga $\mathrm{H}$, Iwasaki $\mathrm{T}$, Tetsumoto S, Jin Y, Ihara S, Minami T, Suzuki M, Nagatomo I, Inoue K, Kida H, Kijima T, et al. Tetraspanin CD151 Protects against Pulmonary Fibrosis by Maintaining Epithelial Integrity. American journal of respiratory and critical care medicine. 2012.

58. Koo BK, Spit M, Jordens I, Low TY, Stange DE, van de Wetering M, van Es JH, Mohammed S, Heck AJ, Maurice MM and Clevers H. Tumour suppressor RNF43 is a stemcell E3 ligase that induces endocytosis of Wnt receptors. Nature. 2012; 488(7413):665-669.

59. Kovalenko OV, Yang XH and Hemler ME. A novel cysteine cross-linking method reveals a direct association between claudin-1 and tetraspanin CD9. Molecular \& Cellular Proteomics. 2007; 6(11):1855-1867.

60. Houle CD, Ding XY, Foley JF, Afshari CA, Barrett JC and Davis BJ. Loss of expression and altered localization of KAI1 and CD9 protein are associated with epithelial ovarian cancer progression. Gynecologic oncology. 2002; 86(1):69-78.

61. Shang X, Lin X, Alvarez E, Manorek G and Howell SB. Tight junction proteins claudin-3 and claudin-4 control tumor growth and metastases. Neoplasia. 2012; 14(10):974985.

62. Rosen DG, Wang L, Atkinson JN, Yu Y, Lu KH, Diamandis EP, Hellstrom I, Mok SC, Liu J and Bast RC, Jr. Potential markers that complement expression of CA125 in epithelial ovarian cancer. Gynecologic oncology. 2005; 99(2):267277.

63. Wang Y, Cheon DJ, Lu Z, Cunningham SL, Chen CM, Luo RZ, Xing D, Orsulic S, Bast RC, Jr. and Behringer RR. 
MUC16 expression during embryogenesis, in adult tissues, and ovarian cancer in the mouse. Differentiation. 2008; 76(10):1081-1092.

64. Jin H, Yu Y, Zhang T, Zhou X, Zhou J, Jia L, Wu Y, Zhou BP and Feng Y. Snail is critical for tumor growth and metastasis of ovarian carcinoma. International journal of cancer Journal international du cancer. 2010; 126(9):21022111.

65. Yang XW, Claas C, Kraeft SK, Chen LB, Wang ZM, Kreidberg JA and Hemler ME. Palmitoylation of tetraspanin proteins: Modulation of CD151 lateral interactions, subcellular distribution, and integrin-dependent cell morphology. Molecular biology of the cell. 2002; 13(3):767-781. 